\title{
COMPARISON OF NUTRITIONAL STATUS OF DOCTORS IN SERVICES HOSPITALS WITH THAT OF EQUIVALENT SOCIAL STRATA IN RELATION TO THEIR EATING HABITS AND PHYSICAL ACTIVITY
}

\author{
Asif Mumtaz Sukhera, Rukhsana Roshan, Sadia Sajjad, Sarah Tanvir, Syed Fawad Mashhadi* \\ Margalla Institute of Health Sciences Rawalpindi Pakistan, *Army Medical College/National University of Medical Sciences (NMUS) Rawalpindi Pakistan
}

\begin{abstract}
Objective: To compare the nutritional status of doctors and non-doctors in relation to their eating habits and physical activity Study Design: Cross sectional study.

Place and Duration of Study: Combined Military Hospital/Military Hospital Rawalpindi, from Sep 2018 to Mar 2019.

Methodology: Anthropometric measurements like weight for age, height for age, weight according to height along with BMI were used as indicators of nutritional status. Data collection tool was built upon food frequency questionnaire and comprised of sociodemographic variables followed by major portions related to general health of respondents, nutritional assessment, dietary patterns and physical activity.

Results: Out of 200 respondents, 100 were physicians working in services hospitals of Army while rest hundred were serving officers non-doctors of similar social status. Mean age of the participants was $35.00 \pm 7.57$ years. There was no significant difference between self-perceived health status of both groups $(p>0.05)$. Dietary habits of physicians were significantly healthy as compared to their counterparts $(p=0.01)$ while physical activity patterns were better amongst non-doctors $(p=0.001)$. Physicians had unhealthy dietary habits, but intake was bit less and cautious as compared to their counterpart group.

Conclusion: Doctors have better dietary patterns, but worse physical activity practices as compared to individuals with similar social strata. Risk factors and nutritional indicators were not different for both groups.
\end{abstract}

Keywords: Body mass index (BMI), Dietary habits, Physical activity.

How to Cite This Article: Sukhera AM, Roshan R, Sajjad S, Tanvir S, Mashhadi SF. Comparison of Nutritional Status of Doctors in Services Hospitals With that of Equivalent Social Strata in Relation to Their Eating Habits and Physical Activity. Pak Armed Forces Med J 2021; 71(6): $2015-2018$. DOI: https://doi.org/10.51253/pafmj.v6i6.7224

This is an Open Access article distributed under the terms of the Creative Commons Attribution License (https://creativecommons.org/licenses/by-nc/4.0/), which permits unrestricted use, distribution, and reproduction in any medium, provided the original work is properly cited.

\section{INTRODUCTION}

Physicians and health worker's own eating habits influence the clientele. The doctor's life is very challenging, especially in countries like Pakistan where the doctor-patient ratio is highly inadequate and the doctors have to look after a huge number of patients' every day, far more as compared to doctors in western countries. ${ }^{1}$ Nutrition is one of the major determining factors in preserving life, promoting growth, maintaining health, resisting diseases, improving achievements in every sphere of life and increasing productivity at individual, family, community and country levels. Any long-term eating habits which do not include proper nutrition will lead to non-communicable disease burden. ${ }^{2}$ Pakistan being developing country is facing huge disease burden due to unhealthy lifestyle. The Center for Disease Control and Prevention (CDC), researchers and health professionals use Body Mass Index (BMI) as the preferred method for determining overweight and obesity in adults, though other

Correspondence: Dr Asif Mumtaz Sukhera, House No 53, Sector D, Boulevard DHA Phase 2 Islamabad Pakistan

Received: 12 Aug 2021; revision received: 10 Oct 2021; accepted: 11 Oct 2021 methods exist and are in use. ${ }^{3}$ Physicians are seen as good and credible sources of health information by patients. Physicians who eat a healthy diet themselves are more likely to counsel their patients about the importance of proper nutrition, furthermore, this counseling is more likely to be effective at inciting positive behavioral changes in patients. ${ }^{4}$

There are almost 38 million deaths yearly due to non-communicable diseases. According to estimates in 2010, NCDs and injuries lead to $62 \%$ of crude deaths and $77 \%$ of age-standardized deaths in Pakistan. ${ }^{5}$ According to estimates by Jafar et al., there is projected increase of crude mortality due to cardiovascular diseases from 125.5-144.4 per 100,000 population per year from 2010-2025.6 Greek physician Galen was probably first one to reveal the importance of physician's well-being and highlighted the importance of self-care. Medical profession makes physician self-sacrificing and they tend to put their profession before their personal requirements. ${ }^{7}$ They are well aware of the adverse effects of physical inactivity but are still unable to look after their own health. ${ }^{8}$ Now there is widespread recognition regarding the importance of physician health due 
to raised awareness of the significance of preventive medicine in general population with physicians being part of it. ${ }^{9}$

This study results can help the health care providers, planners and administrators to know about the nutritional status of the doctors in a services hospital and other social groups, the opportunity of physical activity that they enjoy and can help in planning future course of action to improve the existing situation.

\section{METHODOLOGY}

It was a cross sectional study from September 2018 to March 2019. Ethical approval was sought from Ethical Review board of Combined Mililtary Hospital Rawalpindi and anonymity and confidentiality of participants was maintained.

Inclusion Criteria: Doctors working in $\mathrm{CMH} / \mathrm{PEMH}$ Rawalpindi and serving officers (non-doctors) of similar social strata working in the same garrison were included.

Exclusion Criteria: Individuals who were already patients of hypertension and diabetes were not included in the study.

Informed consent was sought from the research participants. Total 200 including 100 doctors - male of age groups 25-60 years were selected as subjects similarly, 100 officers (non-doctors) were selected for comparison. Nonprobability consecutive sampling technique was used for selection of study participants. Subjects were given a structured questionnaire to provide information on eating habits and their physical activity. All the questions and queries were explained in standardized manner to avoid creating a response bias.

Data were analyzed using Statistical Package for social Science (SPSS) version 21. Mean and Standard Deviation were calculated in descriptive statistics for numerical variables while frequencies and proportions were calculated for categorical variables. Chi square test and $t$ test were used. The $p$-value of $\leq 0.05$ was considered significant.

\section{RESULTS}

The study was conducted on a total of 200 respondents. Mean age and standard deviation of the participants was $35.00 \pm 7.57$ years. Mean age of the doctors was $39.00 \pm 8.00$ years while mean age of the non-doctors' group was $30.70 \pm 3.70$ years. 166 (83\%) of study participants were married and $34(17 \%)$ were unmarried. Mean height, weight, waist measurement, hip measurement, mean BMI, mean systolic blood pressure, BSF (mmol) and HDL (mmol) of the doctors were $174.36 \pm 3.76 \mathrm{~cm}, 74.22 \pm 8.46 \mathrm{~kg}, 39.84 \pm 17.09$ inches, $39.36 \pm 3.19$ inches , $24.38 \pm 2.78,121.60 \pm 11.75$ $\mathrm{mm} \mathrm{Hg}, 121.60 \pm 11.75 \mathrm{mmol}$ and $1.06 \pm 0.10 \mathrm{mmol}$ respectively. While Mean height, weight, waist measurement, hip measurement, mean BMI, systolic blood pressure, BSF (mmol) and HDL (mmol) of nondoctors were $171.66 \pm 17.14 \mathrm{~cm}, 72.16 \pm 9.72 \mathrm{~kg}, 40.18 \pm$ 18.65 inches, $39.46 \pm 3.52$ inches, $23.19 \pm 3.60,118.30 \pm$ $14.41 \mathrm{~mm} \mathrm{Hg}, 4.98 \pm 1.97$ and $1.23 \pm 0.84$ respectively.

There was no significant difference between mean values for all indicators used for nutritional assessment except BMI $(p=0.038)$ and systolic $\mathrm{BP}(p=0.001)$ shown in Table-I.

Table-I: Comparison of Nutritional Status of the Doctors and Non-Doctors.

\begin{tabular}{l|c|c|c}
\hline $\begin{array}{l}\text { Nutritional } \\
\text { Indicators }\end{array}$ & Groups & Mean \pm SD & $\begin{array}{c}p \text { - } \\
\text { value }\end{array}$ \\
\hline Height (cm) & $\begin{array}{c}\text { Doctors } \\
\text { Non-Doctors }\end{array}$ & $\begin{array}{c}174.36 \pm 3.76 \\
171.66 \pm 17.14\end{array}$ & 0.124 \\
\hline Weight (kg) & $\begin{array}{c}\text { Doctors } \\
\text { Non-Doctors }\end{array}$ & $\begin{array}{c}74.22 \pm 8.46 \\
72.16 \pm 9.72\end{array}$ & 0.110 \\
\hline $\begin{array}{l}\text { Waist } \\
\text { measurement at } \\
\text { umbilicus (inches) }\end{array}$ & $\begin{array}{c}\text { Doctors } \\
\text { Non-Doctors }\end{array}$ & $\begin{array}{c}39.84 \pm 17.09 \\
40.18 \pm 18.65\end{array}$ & 0.898 \\
\hline $\begin{array}{l}\text { Hip Measurement } \\
\text { (inches) }\end{array}$ & $\begin{array}{c}\text { Doctors } \\
\text { Non-Doctors }\end{array}$ & $\begin{array}{c}39.36 \pm 3.19 \\
39.46 \pm 3.52\end{array}$ & 0.852 \\
\hline Body Mass Index & $\begin{array}{c}\text { Doctors } \\
\text { Non-Doctors }\end{array}$ & $\begin{array}{c}24.38 \pm 2.78 \\
23.19 \pm 3.60\end{array}$ & 0.038 \\
\hline $\begin{array}{l}\text { Systolic BP } \\
\text { (mmHg) }\end{array}$ & $\begin{array}{c}\text { Doctors } \\
\text { Non-Doctors }\end{array}$ & $\begin{array}{c}121.60 \pm 11.75 \\
118.30 \pm 14.41\end{array}$ & 0.001 \\
\hline BSF (mmol) & $\begin{array}{c}\text { Doctors } \\
\text { Non-Doctors }\end{array}$ & $\begin{array}{l}4.58 \pm 0.67 \\
4.98 \pm 1.97\end{array}$ & 0.292 \\
\hline HDL (mmol) & $\begin{array}{c}\text { Doctors } \\
\text { Non-Doctors }\end{array}$ & $\begin{array}{c}1.06 \pm 0.10 \\
1.23 \pm 0.84\end{array}$ & 0.317 \\
\hline
\end{tabular}

When asked for all the healthy and unhealthy dietary habits, it was found that 64 doctors amongst 100 had healthy dietary habits (vegetable and fruit intake) in contrast to 44 of the officers of similar social strata. Hence, there was statistically highly significant difference amongst dietary habits of doctors and their non-doctor counterparts $p=0.001$ (Table-II).

Table-II: Comparison of healthy dietary habits amongst doctors and non-doctors.

\begin{tabular}{l|c|c|c}
\hline & Doctors & Non-Doctors & $p$-value \\
\hline Healthy & 64 & 44 & 0.001 \\
\cline { 1 - 3 } Unhealthy & 36 & 56 & \\
\hline
\end{tabular}

Amongst two hundred participants, physical activity of 110 participants was graded as bad while for 90 respondents, it was graded as good. 50\% respondents were having vigorous physical activity while $30 \%$ were not having any vigorous physical activity. 
$20 \%$ respondents did not respond on this question. Only $50(46.29 \%)$ respondents amongst those who have responded to the question i.e., were having this vigorous activity more than three days a week. Amongst respondents, 88(69.84\%) were doing moderate physical activity. Only 62 respondents were doing this activity more than three days a week. Only 54 (33.7\%) people amongst 160 respondents were walking to travel from one place to other. Only $92(64.7 \%)$ were having at least 10 minute's continuous walk for more than three days a week. Doctors are less likely to do vigorous activity involving at least ten-minute continuous physical activity that causes large increases in breathing or heart rate (Table-III). There was statistically significant difference in days of vigorous activity as part of work $p$-value $=0.001$.

Table-III: Comparison of vigorous activity amongst both groups (at least 10 minutes continuously).

\begin{tabular}{l|c|c|c}
\multirow{2}{*}{} & \multicolumn{2}{|c|}{ Groups } & \multirow{2}{*}{ p-value } \\
\cline { 2 - 3 } & Doctors & Non-Doctors & \\
\hline Yes & 38 & 62 & \multirow{2}{*}{0.001} \\
\hline No & 46 & 14 & \\
\hline
\end{tabular}

\section{DISCUSSION}

The study was aimed at assessing the health and nutritional status among doctors and non-doctors. The dietary habits and extent of physical activity level among the respondents were also assessed. Doctors were significantly better consumers of various food items compared to non-doctors diet specially in eating raw vegetables $(p=0.011)$ and juice $(p=0.001)$ and in frequent and cautious intake of relatively unhealthy foods.). Pakistan is among those countries where human resource in health sector is at shortage. ${ }^{10}$ Less number of doctors increase their professional commitments to keep them busier and spare less time for themselves. Comparison of anthropometric measures (Height $\mathrm{cm}$, Weight $\mathrm{kg}$ and BMI) between doctors and non-doctors presented obvious difference of height amongst doctors $(174 \pm 3.7 \mathrm{~cm})$ and non-doctors $(171 \pm$ $17 \mathrm{~cm}$ ) declaring the doctors taller with lesser variation in height values. In case of comparing body weight, doctors were observed having increased body weight (74 \pm 8.4$)$ compared to non-doctors followed by increased body mass index values for doctor's clientele $24.3 \pm 2.7)$ and slightly lesser BMI $(23.1 \pm 3.6)$ for nondoctors. However, both type of respondents lie in category of normal body weight and this finding can be justified owing to age of respondents included in study, Myers, et all1. Similar results have been reported from Lemaire study, while in Columbia, $80 \%$ of the professionals had normal BMI. ${ }^{11-12}$ A disagreement at point of increased BMI amongst medical professionals $\left(B M I \geq 25 \mathrm{~kg} / \mathrm{m}^{2}\right)$ constituted $24 \%$, similar to Columbian study (22\%) and a study from Maharashtra (20\%) as against a lower proportion (16\%) in Thailand and Pakistan. ${ }^{12-13}$

Physical activity was being practiced by 100 $(60.6 \%)$ of medical professionals holding normal BMI, while the proportion of practice of physical activity increased as the BMI increased, i.e., 76 (65.5\%) were exercising in the BMI group of $\geq 25 \mathrm{~kg} / \mathrm{m} 2$. Congruence of such findings was also reported by Banerjee et al..$^{14-15}$ Although, it cannot be concluded whether the higher BMI motivated the professionals to indulge in activity that is more physical.

This study reported the proportionate level of healthy doctors being $32 \%$, while proportion of healthy group found in non-doctors being $22 \%$. However, as medical professionals are expected to be healthy in larger proportions than this borderline difference. This finding is thus partially supported by a study conducted in Canada highlighting the relative difference in health status between the two groups. However, Canadian physicians are not only healthy compared with the non-doctors, but with significantly higher proportion being healthy. ${ }^{16-17}$ Nearly all $(92 \%)$ of the (primarily middle-aged) physicians were reported being in at least good health followed by $66 \%$ reported being in very good or excellent health, which is similar to the $70 \%$ of $20-34$-year-old Canadians with very good or excellent health (Statistics Canada, 2009). Only onequarter of Canadian physicians were found with poor physical/mental health. ${ }^{18-19}$

The study found that the trends of eating habits vis-à-vis physical activity of doctors compared to individuals of similar social strata almost followed the international tendency in similar groups. However, it came up that there is lack of nutritional standards and lab analysis of dietary components, which do not give us the exact details of a person's intake with comparison to its need.

\section{CONCLUSION}

Doctors have better dietary patterns, but worse physical activity practices as compared to individuals with similar social strata. Risk factors and nutritional indicators were not different for both groups.

\section{Conflict of Interest: None.}

\section{Authors' Contribution}

SS: Data compilation and proofreading, RR: Intellectual contribution, SS: Intellectual contribution, ST: Intellectual contribution, SFM: Intellectual contribution. 


\section{Nutritional Status of Doctors}

\section{REFERENCES}

1. National Institute of Population Studies (NIPS) [Pakistan] and ICF International. 2013. Pakistan Demographic and Health Survey 2012, Available at: https://dhsprogram.com/pubs/pdf/ fr290/fr290.pdf (Accessed on June 15,2019)

2. Nishtar S, Bile KM, Ahmed A, Amjad S, Iqbal A. Integrated population-based surveillance of non-communicable diseases: the Pakistan model. Am J Prevent Med 2005; 29(5): 102 106.

3. Centre for Disease Control; Body Mass Index (BMI), 2015 (Internet) Available at: https://www.cdc.gov/healthyweight/ assessing/bmi/index.html. (Accessed on Jan 2020).

4. Wiskar K. Physician health: A review of lifestyle behaviors and preventive health care among physicians. BC Med J 2012; 54(8): 419-423.

5. Lozano R, Naghavi M, Foreman K, Lim S, Shibuya K, Aboyans, $\mathrm{V}$, et al. 2012. Global and regional mortality from 235 causes of death for 20 age groups in 1990 and 2010: a systematic analysis for the Global Burden of Disease Study 2010. Lancet 2012: 380(9859): 2095-2128.

6. Jafar TH, Haaland BA, Rehman A, Razzak JA, Bilger M, Naghavi $\mathrm{M}$, et al . Non-communicable diseases and injuries in Pakistan: strategic priorities. Lancet 2013; 381(9885): 2281-2290.

7. Shanafelt TD, Sloan JA, Tm H. The well- being of physicians. Am J Med 2003; 114(6): 513-519.

8. Ghosh AK, SR J. Physician's Health: Time to take care. J Assoc Phy Ind 2008: 56(2): 17-20.

9. World Health Organization (WHO). Fact sheet. 2017, [Internet] Available at: http://www.who.int/nutrition/double-burdenmalnutrition/en/. (Accessed on Jan 16, 2020).
10. Nishtar S. The Gateway Paper: Health Systems in Pakistan, a Way Forward. Pakistan's Health Policy Forum. 2006, [Internet] Available at: http://apps.who.int/iris/bitstream/handle/ 10665 /186463/9789240694811_eng.pdf;jsessionid=B52557AC9FEBF579 00490A601F585BE4? sequence $=1$ (Accessed on Jan 16, 2020)

11. Myers J. Exercise and Cardiovascular Health. Circulat 2003; 107(1): e2-e5.

12. Lemaire JB, Wallace JE, Dinsmore K. Food for thought: An exploratory study of how physicians experience poor workplace nutrition. Nutr J 2011; 10(1): 18.

13. Gandhi H, Vaishali K, Prem V, Vijayakumar K, Adikari P, Unnikrishnan B. A survey on physical activity and non communicable disease risk factors among Physicians in tertiary care Hospitals, Mangalore. Natl J Comm Med 2012: 3(1): 7-13.

14. Banerji MA, Faridi N, Atluri R, Chaiken RL, Lebovitz, HE. Body composition, visceral fat, leptin, and insulin resistance in Asian Indian men. J Clinic Endocrinol Metab 1999; 84(1): 137-144.

15. Warburton DE, Nicol CW, Bredin SS. Health benefits of physical activity: the evidence. Can Med Assoc J 2006; 174(1): 801-809.

16. Canadian Community Health Survey. Statistics Canada. 2010 [Internet] Available at: https://www23.statcan.gc.ca/imdb/ p2SV.pl?Function $=$ getSurvey\&SDDS $=3226$

17. Frank E, Segura C. Health practices of Canadian physicians. Can Fam Phy 2009; 55(8): 810-811.

18. Canada physician health institute. Available at: https:// www.cma.ca/En/Pages/Physician-health-wellness.aspx (Accessed on Sep 23, 2020).

19. National Physician Survey. Mississauga. College of Family Physicians of Canada. [Internet] Available at: www.nationalphysiciansurvey.ca/nps/2007_Survey/2007nps-e.asp. [Accessed Jan 15, 2020]. 